\title{
Collection of corneal impression cytology directly on a sterile glass slide for the detection of viral antigen: An inexpensive and simple technique for the diagnosis of HSV epithelial keratitis - A pilot study Sreedharan Athmanathan ${ }^{* 1}$, Sesha Reddy Bandlapally ${ }^{1}$ and Gullapalli N Rao ${ }^{2}$
}

Address: ${ }^{1}$ Jhaveri Microbiology Center, Hyderabad Eye Research Foundation, Hyderabad, India and ${ }^{2}$ Cornea Services L. V. Prasad Eye Institute, L. V. Prasad Marg, Banjara Hills, Hyderabad, India

E-mail: Sreedharan Athmanathan* - sreedhar@lvpeye.stph.net; Sesha Reddy Bandlapally - sreedhar@lvpeye.stph.net; Gullapalli N Rao - gnrao@lvpeye.stph.net

*Corresponding author

Published: 19 September 2001

BMC Ophthalmology 200I, I:3
Received: 23 June 2001

Accepted: 19 September 2001

This article is available from: http://www.biomedcentral.com//47/-24/5/I/3

(C) 200I Athmanathan et al; licensee BioMed Central Ltd. Verbatim copying and redistribution of this article are permitted in any medium for any noncommercial purpose, provided this notice is preserved along with the article's original URL. For commercial use, contact info@biomedcentral.com

\begin{abstract}
Background: Herpes simplex keratitis (HSK) is a sight threatening ocular infection and occurs worldwide. A prompt laboratory diagnosis is often very useful. Conventional virology techniques are often expensive and time consuming. We describe here a highly economical, simple, rapid and sensitive technique for the collection of impression cytology, for the laboratory diagnosis of HSK.
\end{abstract}

Methods: Fifteen patients with a clinical diagnosis of HSK (either dendritic or geographic ulcers) and five patients with other corneal infections (Mycotic keratitis, $n=3$, Bacterial keratitis, $n=2$ ) were included in the study. Corneal impression cytology specimens were collected using a sterile glass slide with polished edges instead of a membrane, by pressing the surface of one end of the slide firmly, but gently on the corneal lesion. Additionally, corneal scrapings were collected following the impression cytology procedure. Impression cytology and corneal scrapings were stained by an immunoperoxidase or immunofluorescence assay for the detection of HSV-I antigen using a polyclonal antibody to HSV-I. Corneal scrapings were processed for viral cultures by employing a shell vial assay.

Results: This simple technique allowed the collection of adequate corneal epithelial cells for the detection of HSV-I antigen in a majority of the patients. HSV-I antigen was detected in I2/I5 (80\%) cases while virus was isolated from 5/I5 (33.3\%) patients with HSK. All the patients with a clinical diagnosis of HSK ( $n=15)$ were confirmed by virological investigations (viral antigen detection and/ or viral cultures). HSV-I antigen was detected in the impression cytology smears and corneal scrapings in $11 / 15(73.3 \%)$ and $12 / 15(80 \%)$ of the patients, respectively $(P=1.00)$. None of the patients in the control group were positive for viral antigen or virus isolation. Minimal background staining was seen in impression cytology smears, while there was some background staining in corneal scrapings stained by the immunoassays.

Conclusions: Collection of impression cytology on a sterile glass slide is a simple, rapid and inexpensive technique for the diagnosis of HSK. Immunological techniques applied on such smears provide virological results within 2-5 hours. This technique could be modified for use in the diagnosis of other external eye diseases, which needs further evaluation. 


\section{Background}

Herpes Simplex Keratitis (HSK) is a sight threatening ocular infection often caused by HSV-1. It is a leading cause of corneal blindness and occurs worldwide [1]. HSK usually occurs in its typical form as a dendritic or geographical corneal ulcer. However, there are reports of atypical HSK [2]. There can be a high degree of overlap between the ocular manifestations of HSV-1 and those of other infections [3]. A specific and rapid laboratory diagnosis of HSK is essential for the initiation of specific antiviral therapy. Further, complications arising from misdiagnosis and inappropriate treatment can be avoided [3]. A variety of techniques have been employed for the rapid diagnosis of HSK $[4,5]$. Many of these techniques are expensive, time consuming and may not be available in all settings. Impression cytology has been employed for the rapid diagnosis of superficial viral infections [6]. It is one of the most preferred techniques in ocular surface sampling in dry eye, keratitis and conjunctivitis [7]. Conventionally, impression cytology is collected using cellulose acetate filter paper [8], Biopore membrane [6] or Nitrocellulose membrane [9]. These membranes are expensive and may not be available in all laboratories. We describe here an economical, simple and rapid technique for the collection of impression cytology, for the detection of viral antigen.

\section{Methods}

Fifteen patients with a clinical diagnosis of HSK (either dendritic or geographic ulcers) and five patients with other corneal infections (Mycotic keratitis, $\mathbf{n}=3$, Bacterial keratitis, $n=2$ ) were included in the study. Informed consent was obtained from all the patients included in this study and the study conformed to the guidelines stipulated by our institutional research forum. Samples were collected following instillation of a topical anaesthetic (4\% Lignocaine hydrochloride or $0.5 \%$ Proparacaine hydrochloride). Corneal impression cytology specimens were collected using a sterile glass slide (Blue Star Micro Slides, Polar Industrial Corporation, Bombay, India). These slides are made from selected optically flat micro-glass, the edges are polished (therefore, the edges are not sharp), available in lint free packing and are packed under controlled conditions. The slides were initially washed with distilled water and immersed for $24 \mathrm{~h}$ in potassium dichromate-sulphuric acid cleaning solution (This solution was prepared by adding $63 \mathrm{gms}$ of potassium dichromate to $35 \mathrm{ml}$ of distilled water. Concentrated sulphuric acid $(1 \mathrm{~L})$ was then added slowly down the sides of the bottle held in an ice bath with intermittent shaking to dissipate the heat generated). Slides were removed and thoroughly washed in tap water, rinsed in distilled water, and air-dried. They were packed in aluminium foil and sterilized by hot air oven for $1 \mathrm{~h}$ at $160^{\circ} \mathrm{C}$. This method of cleaning slides ensures that the charge of the glass surface is not alkaline and therefore, renders the surface suitable for cell adhesion (an alkaline surface is unsuitable for cell adhesion and is caused by alkaline detergents). Impression cytology smears were obtained by pressing the surface of one end of the slide firmly, but gently on the corneal lesion (Fig. 1). A single impression cytology smear was collected from all the patients except in two cases with classical dendritic ulcers and a case of bacterial keratitis, wherein additional smears were collected for Papanicolaou staining. Corneal scrapings were collected from these patients following the impression cytology procedure for the detection of viral antigen [6] and viral cultures [5]. Impression cytology specimens and smears made from corneal scrapings were air dried for 30 minutes at room temperature and fixed in acetone for 30 minutes at $-20^{\circ} \mathrm{C}$. Smears were stained by an immunoperoxidase or immunofluorescence assay for the detection of HSV-1 antigen using a polyclonal antibody to HSV-1, as described elsewhere [6]. The entire smear was screened for positively stained cells (infected cells) and smears were graded as "Positive" for viral antigen only when $>40-50 \%$ of the cells/ HPF were stained. Viral cultures were performed employing the shell vial assay [5] using vero/ A 549 or BHK21 cell line. Corneal scrapings collected from patients with infectious keratitis of non-viral origin were processed for etiological agents as described earlier [10].

Statistical analysis was performed on results using a computer assisted statistical program (Epi Info, revision $6.04 \mathrm{~b}, \mathrm{CDC}$, USA). Chi square test for proportions (with Yates correction when necessary) was used and $P$ value was considered significant if less than 0.05.

\section{Results}

This simple technique allowed the collection of adequate corneal epithelial cells (10-20 epithelial cells/HPF) for the detection of HSV-1 antigen in a majority of the patients. Most of the smears showed superficial corneal epithelial cells. Some smears showed rounded up corneal epithelial cells. Adequate cells could not be collected in one patient. HSV-1 antigen was detected in 12/15 (80\%) cases while virus was isolated from $5 / 15(33.3 \%)$ patients with HSK. Virus isolation alone was positive in $3 / 15 \mathrm{pa}-$ tients. All the patients with a clinical diagnosis of HSK (n $=15$ ) were confirmed by virological investigations (viral antigen detection and/or viral cultures).

HSV-1 antigen was detected in the impression cytology smears (Figs. 2, 3) and corneal scrapings (Fig. 4) in 11/15 $(73.3 \%)$ and $12 / 15(80 \%)$ patients, respectively $(P=$ 1.00). All the corneal scraping specimens which were found positive for the presence of viral antigen $(n=12)$ were also positive by impression cytology $(n=11)$ except in one case. Adequate cells could not be collected in this 


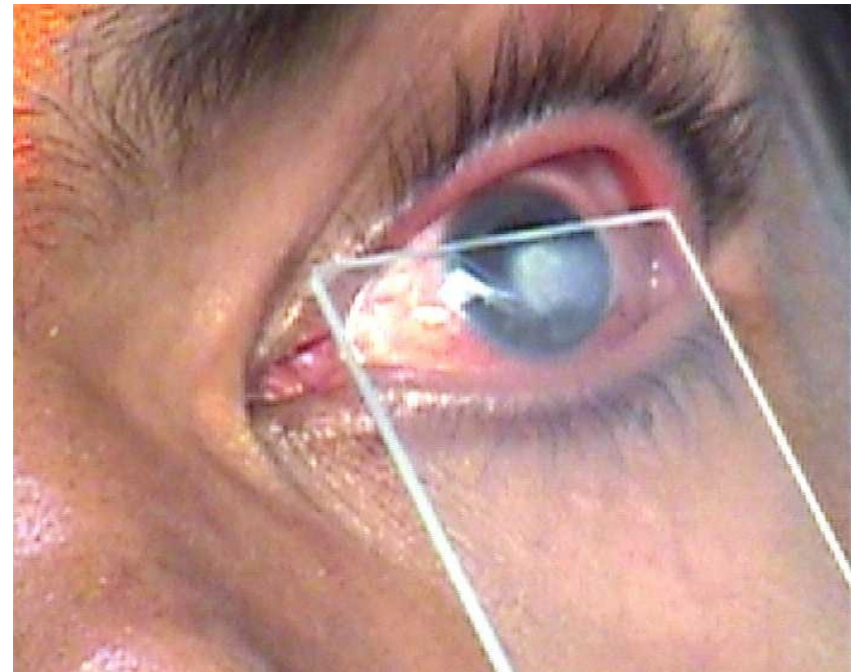

\section{Figure I}

Collection of impression cytology. Impression cytology being collected From a patient with herpes simplex keratitis, using a sterile glass slide with polished edges.

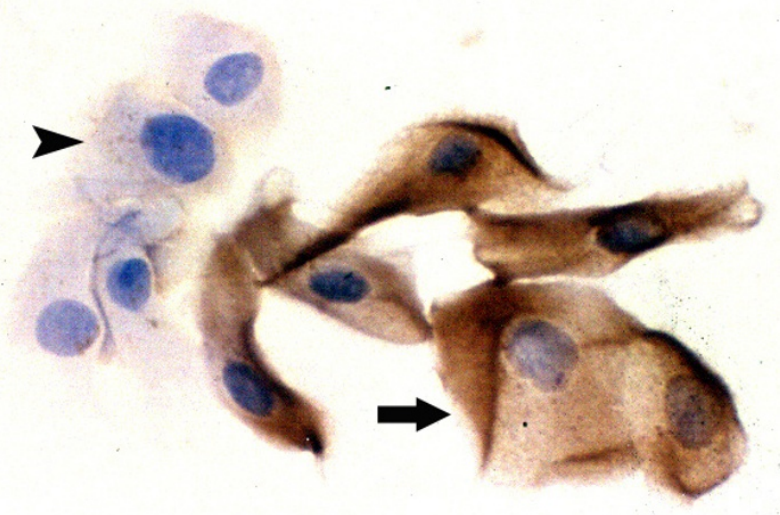

Figure 2

Detection of HSV-I antigen. An impression cytology smear obtained from a patient with HSK showing the presence of corneal epithelial cells positive for viral antigen (arrow). Many antigen negative cells are also seen (arrow head). Note the absence of background staining. Indirect immunoperoxidase assay, $\times 500$.

case. Minimal background staining was seen in impression cytology smears while there was a disturbing background in corneal scrapings stained by the immunological methods.

Papanicolaou stained impression cytology smears showed presence of multinucleated giant cell (Fig. 5), koilocytic changes (Fig. 6) and inflammatory cells (Fig. 7).

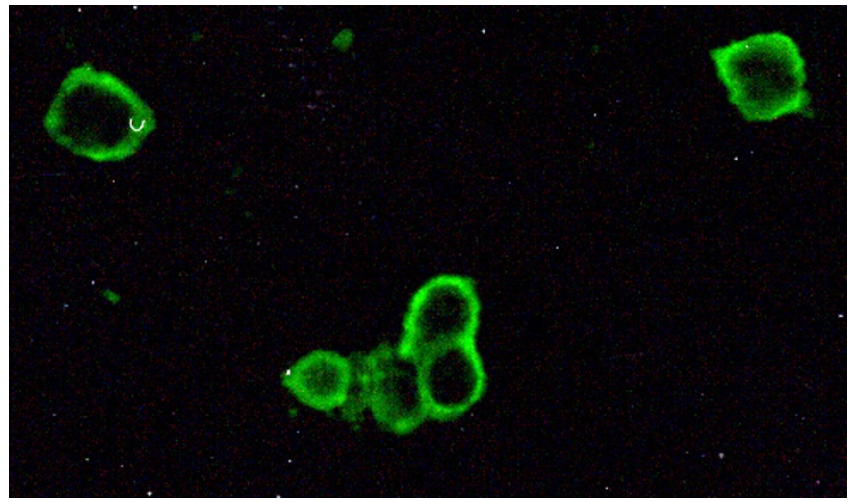

Figure 3

Detection of HSV-I antigen. An impression cytology smear obtained from a patient with HSK showing the presence of rounded up corneal epithelial cells positive for viral antigen. Infected cells show brilliant apple green fluorescence. Note the absence of background staining. Indirect immunofluorescence assay, $\times 500$.

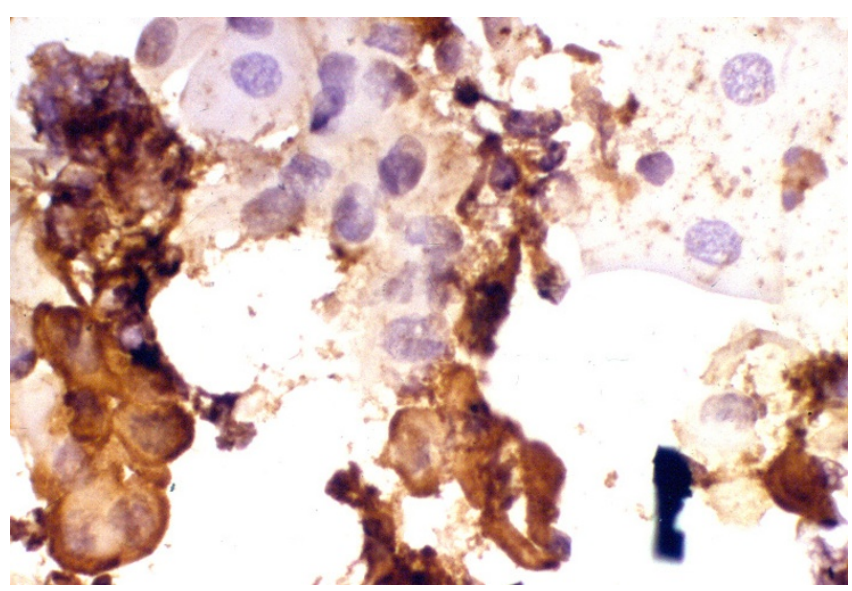

\section{Figure 4}

Detection of HSV-I antigen. A smear made from corneal scraping obtained from a patient with HSK showing the presence of corneal epithelial cells positive for viral antigen (cells stained brown). Many antigen negative cells are also seen (cells stained bluish purple). Note the presence of troublesome background staining. Indirect immunoperoxidase assay, $\times 500$.

None of the patients in the control group (non-HSV keratitis) were positive for viral antigen (Fig. 8) or virus isolation.

\section{Discussion}

Impression cytology is a non-invasive technique for the diagnosis of external eye diseases. It has not been extensively used despite its diagnostic potential because of 


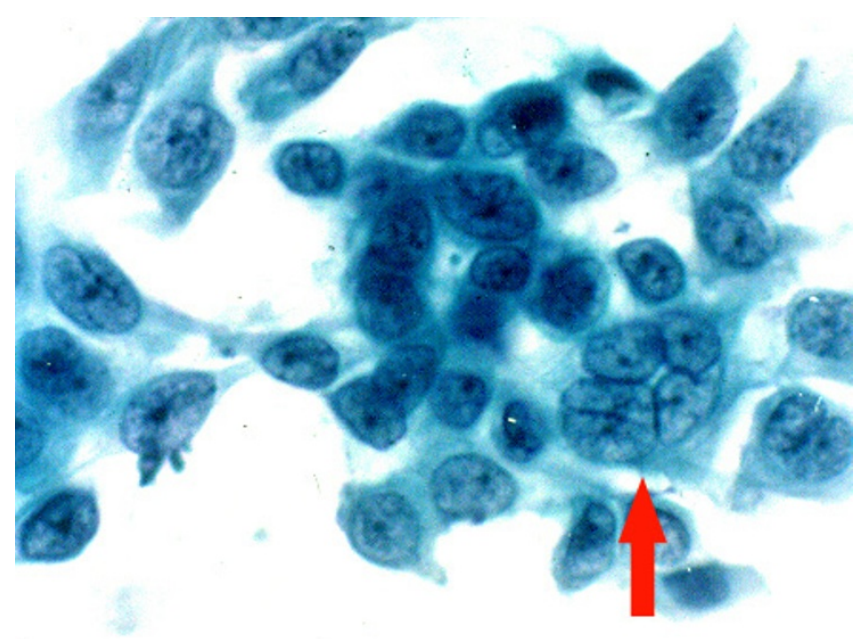

Figure 5

Impression cytology smear stained by Papanicolaou stain. This specimen was obtained from a patient with a classical dendritic ulcer clinically diagnosed as HSK. Note the presence of a multinucleated giant cell (arrow), $\times 500$.
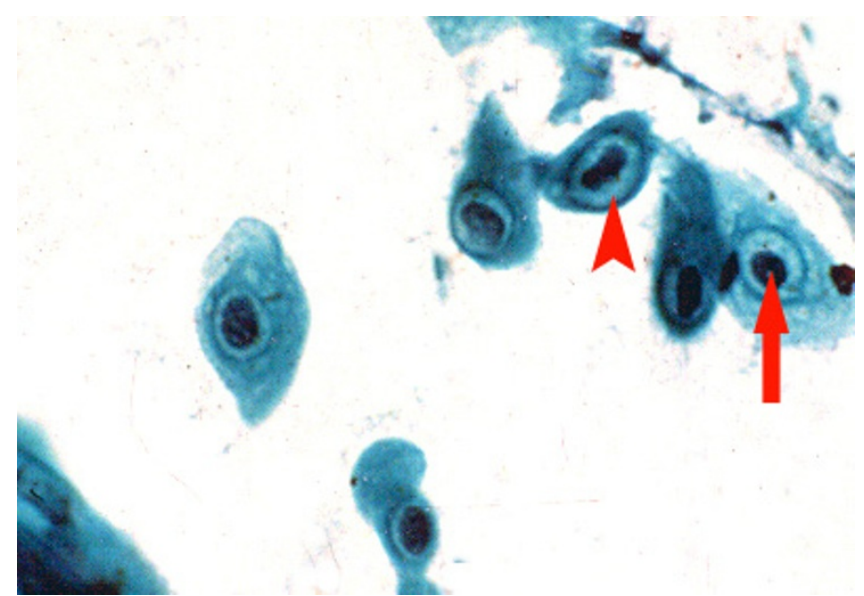

\section{Figure 6}

Impression cytology smear stained by Papanicolaou stain. Note the presence of koilocytic changes in the epithelial cells. Koilocytic changes like condensed chromatin (arrow) and a perinuclear halo (arrow head) are seen, $\times 500$.

technical inconvenience in the use of conventional membranes and its non-availability in many settings.

We have described here a highly economical, simple and rapid technique for the collection of impression cytology for the diagnosis of HSK, by using an ordinary glass slide. Our preliminary data shows that this technique is comparable to collection of corneal scrapings, especially for the detection of viral antigen (11/15 [73.3\%] versus 12/15

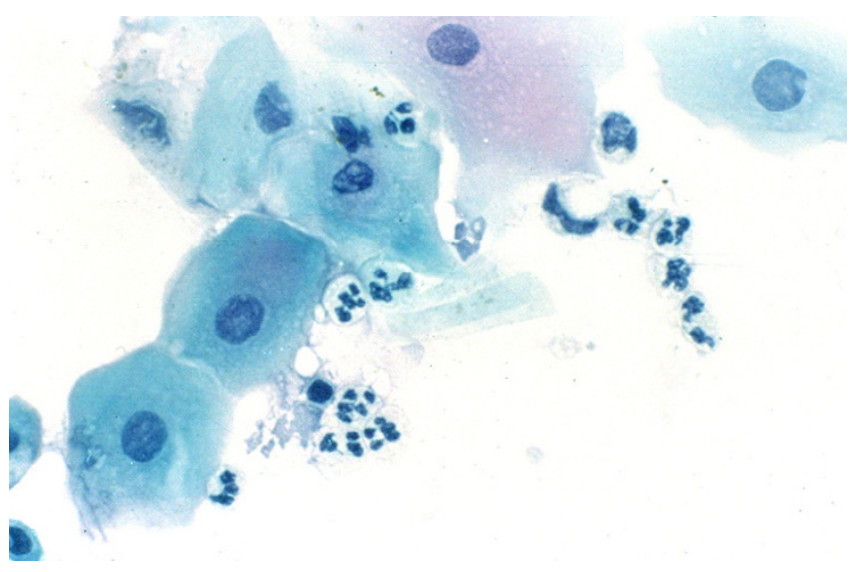

Figure 7

Impression cytology smear stained by Papanicolaou stain. This specimen was obtained from a patient with bacterial keratitis. Note the presence of superficial epithelial cells and polymorphonuclear neutrophils, $\times 500$.

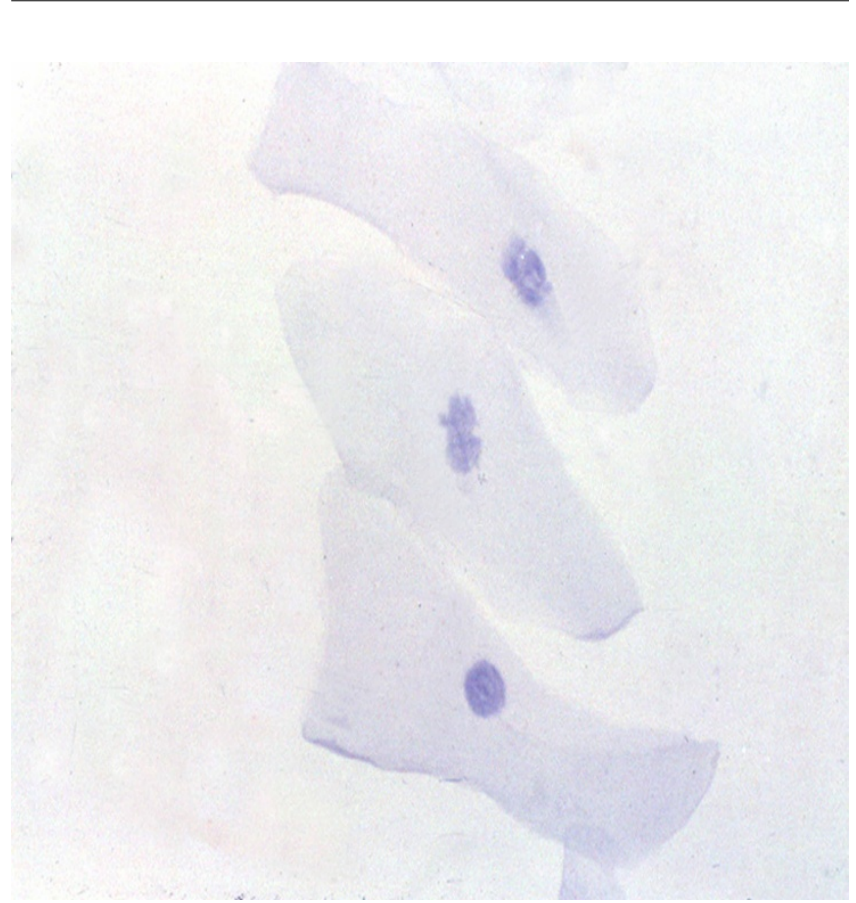

Figure 8

Detection of HSV-I antigen. Impression cytology smear showing corneal epithelial cells from a patient with mycotic keratitis showing the absence of viral antigen. Note the absence of background staining. Indirect immunoperoxidase assay, $\times 500$.

[80\%], $P=1.00)$. The result was not statistically significant.

Qualitatively, interpretation of antigen detection in impression cytology smears was very easy, since the back- 
ground staining was virtually negligible. Interpretation of smears stained by the immunofluorescence assay was easier than smears stained by the immunoperoxidase aassay, since the background staining was somewhat lesser in the former. Additional advantage of this technique is that the glass slides are totally devoid of background fluorescence in comparison to cellulose acetate and biopore membranes. The specificity and sensitivity of this technique was $100 \%$ and $73.3 \%$ respectively and was comparable to that of corneal scrapings (specificity: 100\% and sensitivity: 80\%), for the detection of viral antigen. Earlier reports using membranes have shown better sensitivity $[6,11]$. This could be attributed to the inherent property of the membrane devices to which the cells adhere effectively resulting in the collection of a large number of cells[6]. In contrast, most of the smears made from corneal scrapings which were positive for viral antigen (9/12) showed a troublesome background staining, though the antigen positive cells (virus infected cells) could be identified from uninfected cells.

Quantitatively, adequate number of cells (10-20 epithelial cells/HPF) could be collected in most of the cases. However, the disadvantage of impression cytology was that in a small proportion of cases (2/15 [13.3\%]), the material obtained was inadequate. This may contribute to antigen negativity. Similar findings have been reported by Yagmur et al. These authors have shown that the cell number was inadequate for diagnosis in $21 \%$ of the samples observed by impression cytology [7]. The numbers of cells, which can be collected using a glass slide, are probably small when compared to a membrane. Nevertheless, the results of our preliminary study are encouraging. This may be attributed to the method we have adopted for cleaning the slides, which improves cell adhesion.

Considering the ease of performance and cost per patient, this technique was very easy to perform and proved to be very economical. The advantage of this technique is that the cells are collected directly onto the slide. Handling the slide for various staining procedures is easy and permanent mounts can be stored conveniently when immunoperoxidase assays are used. It is worthwhile to note that the cost (figures are based on the actual cost of procuring these utilities in a developing country like India) of collecting an impression cytology on a glass slide is approximately $\$ 0.01$ whereas the cost of a millipore membrane is $\$ 2.00$.

The impression cytology smears can be used for other staining procedures like PAP and Giemsa stain. Characteristic features of a viral infection, for example, the presence of multinucleated giant cell (Fig. 6), koilocytic changes in epithelial cells (Fig. 7) and inflammatory cells
(Fig. 8), all can be well-delineated in corneal scrapings and impression cytology smears. We have collected impression cytology for such staining procedures in three patients. Further studies are warranted to assess these procedures. Further, impression cytology from other sites like conjunctiva and skin vesicles can be collected by this method, especially for direct staining techniques. This needs further evaluation.

Based on our preliminary results, the technique we have described may be as useful as collection of impression cytology using Biopore membranes and cellulose acetate papers, as described by other authors[6,8,9]. We believe that this procedure is as safe as collection of corneal scraping which is routinely obtained using blade no. 15 on a Bard Parker handle. We did not encounter any difficulty nor untoward incidents during the collection process using the method we have described. It is worthwhile to note that we have used special glass slides with polished edges. Nevertheless, the glass slides can further be modified wherein the square edges can be rounded off. Alternatively, Perspex cover slips can be used for the collection of cells [12]. However, handling a Perspex cover slip may not be convenient when compared to a glass slide, especially for the collection of corneal impression cytology. This technique can be considered as a suitable alternative procedure where facilities for such devices (Biopore membranes, cellulose acetate paper) are not available. However, our results should be considered with caution, since the sample size is small.

\section{Conclusions}

In conclusion, collection of impression cytology on a sterile glass slide followed by viral antigen detection is an inexpensive, simple and rapid technique for the diagnosis of HSK. Immunological techniques can be applied on such smears, which can provide virological results within 2-5 hours. This technique could be modified for use in the diagnosis of other external eye diseases and various staining procedures, which needs further evaluation.

\section{Competing interests}

None declared

\section{Acknowledgements}

This study was supported by the Hyderabad Eye Research Foundation. The authors thank the patients for participating in this study, and Mr. S. B. N. Chary for assistance in photography.

\section{References}

I. Yamamoto SY, Shimomura Y, Kinoshita S, Nishida K, yamamoto R, Tano $Y$ : Detection of herpes simplex virus DNA in human tear film by polymerase chain reaction. Am J Ophthalmol 1994, I I 7:160-163

2. Koizumi N, Nishida K, Adachi W, Adachi W, tei M, Honma Y, Dota A, Sotozono C, Yokoi N, Yamamoto S, Kinoshita S: Detection of herpes simplex virus DNA in atypical epithelial keratitis using polymerase chain reaction. Br J Ophthalmol I 999, 83:957-960 
3. Asbell PA, Torres MA, Kamenar T, Botone EJ: Rapid diagnosis of ocular herpes simplex infections. Br J Ophthalmol 1995, 79:473475

4. Kowalski RP, Gordon YJ: Evaluation of immunologic tests for the detection of ocular herpes simplex virus. Ophthalmology 1989, 96:1583-1586

5. Walpita $\mathrm{P}$, Darougar $\mathrm{S}$, Thaker $\mathrm{U}$ : A rapid and sensitive culture test for detecting herpes simplex virus from the eye. $\mathrm{Br} J \mathrm{Oph}$ thalmol 1985, 69:637-639

6. Thiel MA, Bossart W, Bernauer W: Improved impression cytology techniques for the immunopathological diagnosis of superficial viral infections. $\mathrm{Br}$ J Ophthalmol 1997, 81 :984-988

7. Yagmur M, Ersoz C, Ersoz TR, Varinli S: Brush technique in ocular surface cytology. Diagn Cytopathol I 997, I7:88-9I

8. Arora I, Singhvi S: Impression debridement of corneal lesions. Ophthalmology 1994, 101:1935-1940

9. Nakagawa $\mathrm{H}$, Uchida $\mathrm{Y}$, Takamura E, Nakagawa $\mathrm{Y}$, Araki $\mathrm{H}$, Watanabe M: Diagnostic impression cytology for herpes simplex keratitis. Jpn J Ophthalmol 1993, 37:505-513

10. Kunimoto DY, Sharma S, Reddy KM, Gopinathan U, Jeevan Jyothi, Miller D, Rao GN: Microbial keratitis in children. Ophthalmology 1998, 105:252-257

II. Simon MW, Miller D, Pflugfelder SC, Murchison JF, Huang AJ, Atherton SS: Comparison of immunocytology to tissue culture for diagnosis of presumed herpes virus dendritic epithelial keratitis. Ophthalmology 1992, 99:1408-1413

12. Hirji NK, Larke JR: Conjunctival impression cytology in contact lens practice. J Br Contact Lens Assoc 198I, 4:159-16I

Publish with BioMed Central and every scientist can read your work free of charge

"BioMedcentral will be the most significant development for disseminating the results of biomedical research in our lifetime."

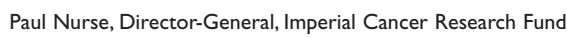

Publish with BMC and your research papers will be:

- available free of charge to the entire biomedical community

- peer reviewed and published immediately upon acceptance

- cited in PubMed and archived on PubMed Central

- yours - you keep the copyright 